\title{
Alveolar Ridge Preservation of an Extraction Socket of Fractured Maxillary Lateral Incisor
}

\author{
Hasan Ayberk Altug*, Abdullah Tugrul Coskun, Aydın Ozkan, Tamer Zerener, \\ Metin Sencimen \\ Department of Oral and Maxillofacial Surgery, Gulhane Military Medical Academy, Ankara, Turkey \\ Email: *aybork@yahoo.com
}

Received 10 December 2015; accepted 19 January 2016; published 22 January 2016

Copyright (C) 2016 by authors and Scientific Research Publishing Inc.

This work is licensed under the Creative Commons Attribution International License (CC BY).

http://creativecommons.org/licenses/by/4.0/

CC) (i) Open Access

\begin{abstract}
Background: Alveolar ridge resorption still continues to be a problem in oral surgery. Cause of bone resorption is including tooth extraction, periodontal disease and inflammatory periapical pathologies. Various methods and materials have been suggested to minimize this resorption. Aim: Goal of this case report is to present alveolar ridge preservation (ARP) following horizontally fractured maxillary lateral incisor with allograft in the aesthetic zone. Case presentation: 30-yearold female patient with fractured tooth was treated by grafting and insertion dental implant. Fractured tooth extraction was performed and extraction socket augmentation was performed by allograft and covered with collagen membrane. Augmented area was treated with bone-level implant. Definitive prosthesis single-tooth porcelain-fused-to-zirconia restorations were fabricated. Conclusions: Before implant insertion, extraction and grafting socket procedure is appropriate treatment for of fractured teeth with granulation tissue.
\end{abstract}

\section{Keywords}

Dental Trauma, Maxilla, Incisor, Allograft, Dental Implant

\section{Introduction}

Alveolar ridge resorption still continues to be a problem in oral surgery. Cause of bone resorption includes tooth extraction, periodontal disease and inflammatory periapical pathologies. Age, gender, systemic diseases (diabetes, etc.) and trauma are the predisposing factors that affect alveolar bone resorption [1]-[3]. Root fractures caused by a trauma constitute approximately $7 \%$ of dental injuries and may give rise to complicated tooth extraction. This situation may cause the placement of dental implants to be difficult. Alveolar ridge resorption is accelerated after tooth extraction in the following six months [4]-[6].

"Corresponding author. 
Various methods and materials have been suggested in order to minimize this resorption [3] [7]-[11]. Although guided bone regeneration increases alveolar ridge height and width, because of its various difficulties, socket preservation has become a more popular method lately [9].

Aim of this case report is to present alveolar ridge preservation (ARP) following horizontally fractured maxillary lateral incisor with allograft in the aesthetic zone. Allograft was performed immediately in an extraction socket for implant region development.

\section{Description of the Case}

A 25-year-old female patient has referred to our clinic with infection complaints of the left maxillary lateral incisor. As the patient told us, her anterior maxillary teeth were injured as a result of being hit by a stone four years ago. Root canal treatment was applied to right maxillary central incisor and left maxillary lateral incisor (had horizontal fracture in the middle third) by patient's local dentist (Figure 1(a) and Figure 1(b)).

In radiographic examination by Cone Beam CT (CBCT), the left maxillary lateral incisor fractured horizontally had a root-filling and a granulation tissue in middle thirds (Figure 2). The luxation of this tooth was determined clinically (Figure 3).

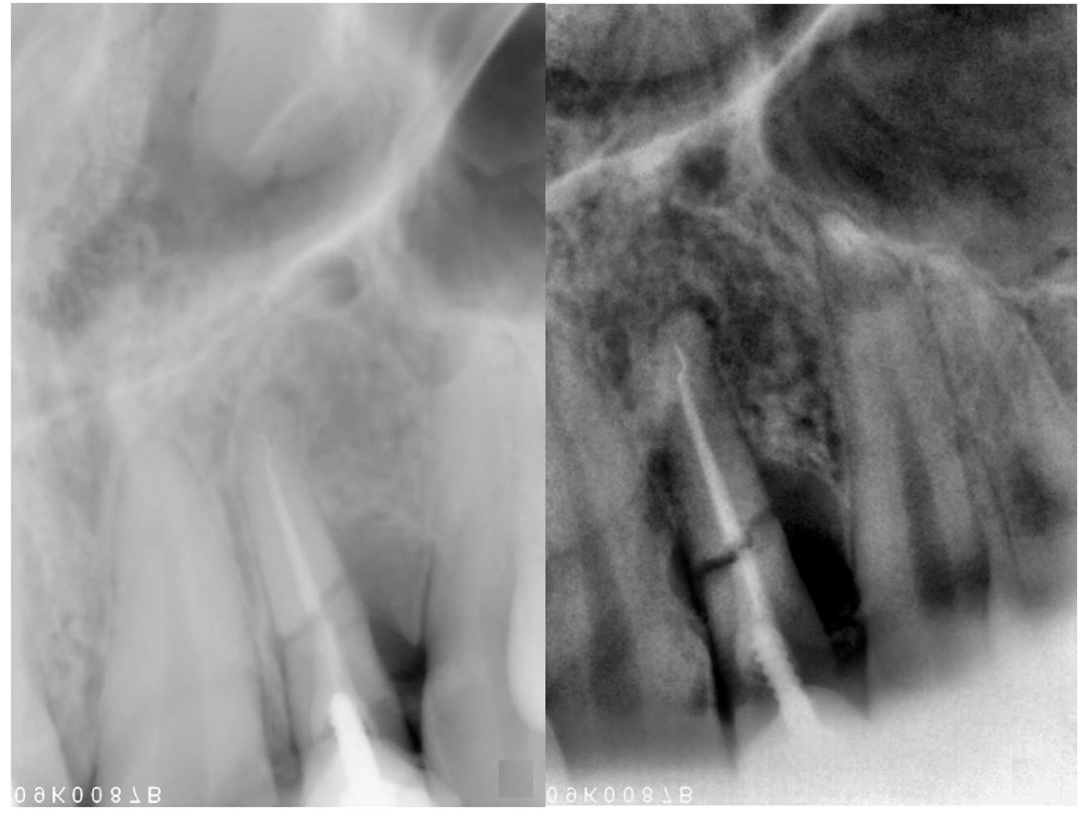

(a) (b)

Figure 1. (a) A periapical radiograph taken four years ago; (b) A periapical radiograph taken two years ago. Granulation tissue was seen.

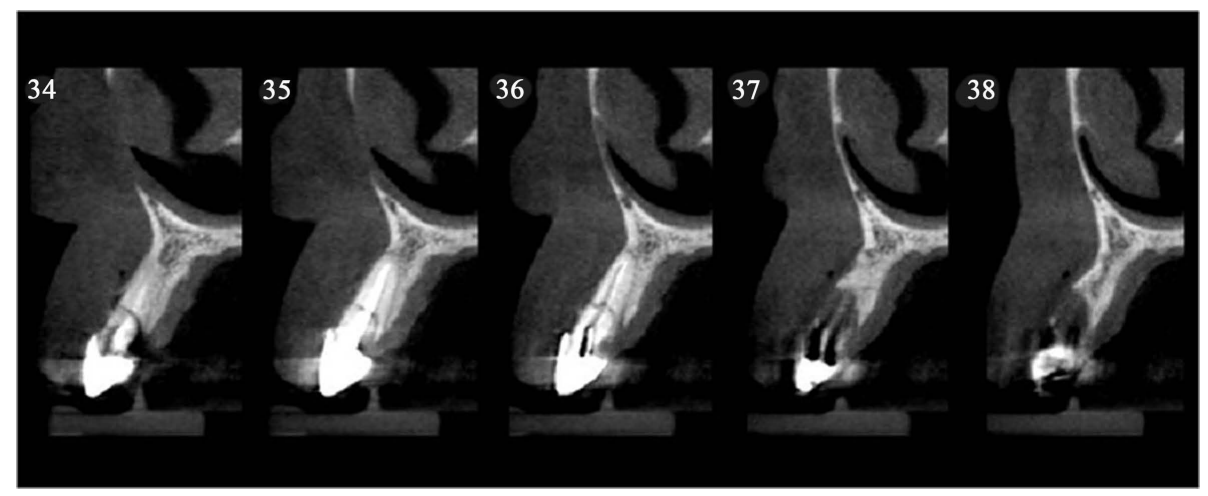

Figure 2. A CB-CT of the left maxillary lateral incisor horizontally fractured. 


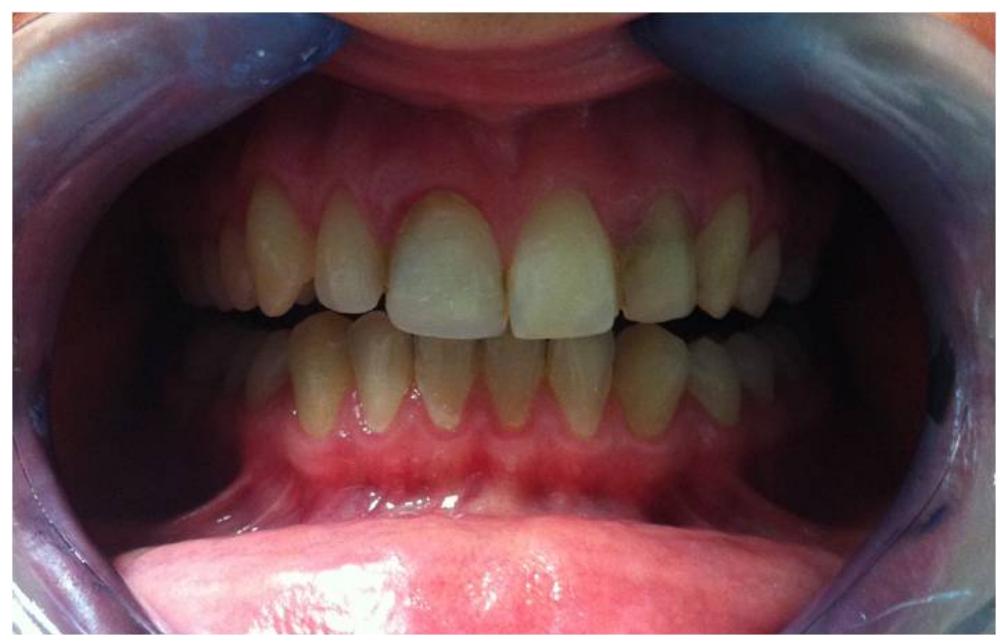

Figure 3. Preoperative intraoral view of female patient.

Patient informed about potential risks of operation. Her consent form was taken. Local infiltration was administered using articaine hydrochloride 4\% with epinephrine 1:200,000 (Ultracaine DS, Hoechst Marion Roussel). Envelope flap design was applied to expose bone margin of the tooth to be extracted. \#14 extraction was performed and socket was curetted to remove any granulation tissue (Figure 4(a) and Figure 4(b)). Extraction socket augmentation was performed by mineralized solvent-dehydrated bone allograft (Puros, 250 - 1000 micron particle size) and covered with collagen membrane (BioMend Extend, $15 * 20 \mathrm{~mm}$ ). The wound was closed with 4 - 0 nylon suture. After surgery, patient used amoxicillin (500 mgr, four times a day for five days), chlorhexidine oral rinse $(0.12 \%$, six times a day for 10 days). Sutures were removed 10 days after the surgery.

The augmented area (Figure 5) was treated with bone-level implant (Institute Straumann AG, Waldenburg, Switzerland) after six months. Implant lengt 12 with 3.3-mm diameter (Figure 6). Prosthetic procedure was performed after four months (Figure 7).

Allograft was performed immediately in the extraction socket for implant region development. The primary stability of inserted implant was 53 ISQ and secondary stability was 71 ISQ. Postoperative healing follow-up was uneventful. Definitive prosthesis single-tooth porcelain-fused-to-zirconia restorations were fabricated for all four anterior incisors. There were no symptoms like infection, bleeding or pocket around the implant.

\section{Discussion}

Maxillofacial trauma can disrupt the integrity of the tooth, therefore its extraction might be inevitable. Major etiological factor of alveolar bone resorption is the extraction of a tooth [12]-[14]. The presence of sufficient buccal alveolar bone is essential for alveolar ridge preservation. Bone graft as autogenic, allogenic, and heterogenic with or without barrier membrane, synthetic materials, platelet rich fibrin gives a good result for ARP [3] [6] [7] [9] [11] [15].

In contrast to our case, the horizontal fractures are described in the central maxillary incisors in the literature. These conditions lead to aesthetic, functional, and healing problems [16]. According to Andreason et al. [4], recovery of root fractures is divided into four different types: a) recovery with hard tissue, b) recovery with conjunctive tissue interposition, c) recovery with bone and conjunctive interposition between the fragments, and d) recovery with granulation tissue between the fragments. Recovery was with granulation tissue all over the middle thirds of root in our case at the end of four years. Therefore, we extracted the left maxillary lateral incisor, persevered and augmented the socket, and inserted bone-level implant. Although Gu et al. [17] asserted tissue-level implant uses in anterior maxilla, many authors [18] [19] published articles which state that bone-level implant is a more concise surgical procedure and it leads to less bone resorption.

Covani et al. [20] reported that immediate implant placement is a valid treatment which induces predictable results. In this current case, we have extracted fractured tooth, augmented the socket and inserted dental implant step by step because of the granulation tissue around the root.

Barone et al. [3] indicated that use of corticocancellous porcine substitute and resorbable membrane succeed in reducing alveolar contour from remodeling when compared to non-preserved extraction sockets. 


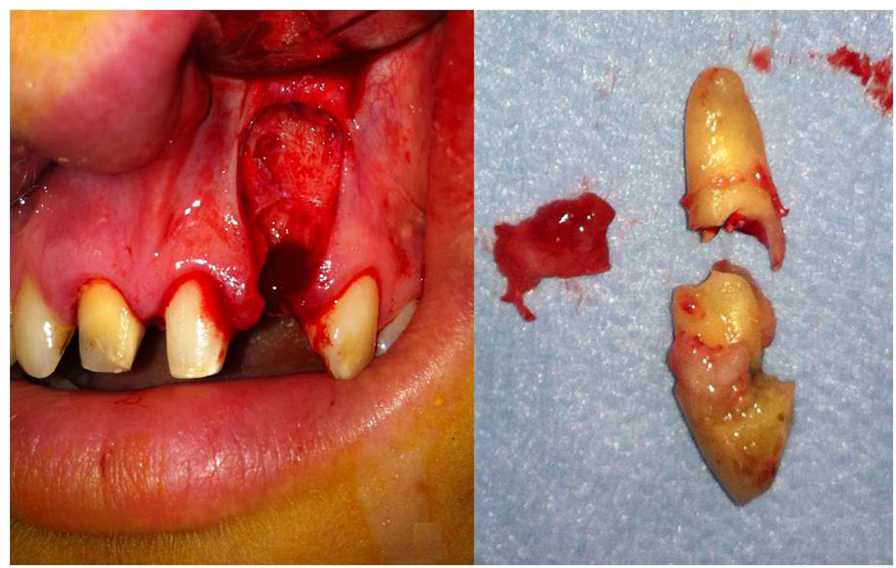

(a)

(b)

Figure 4. (a) A view of extraction area; (b) Extracted left maxillary lateral incisor.

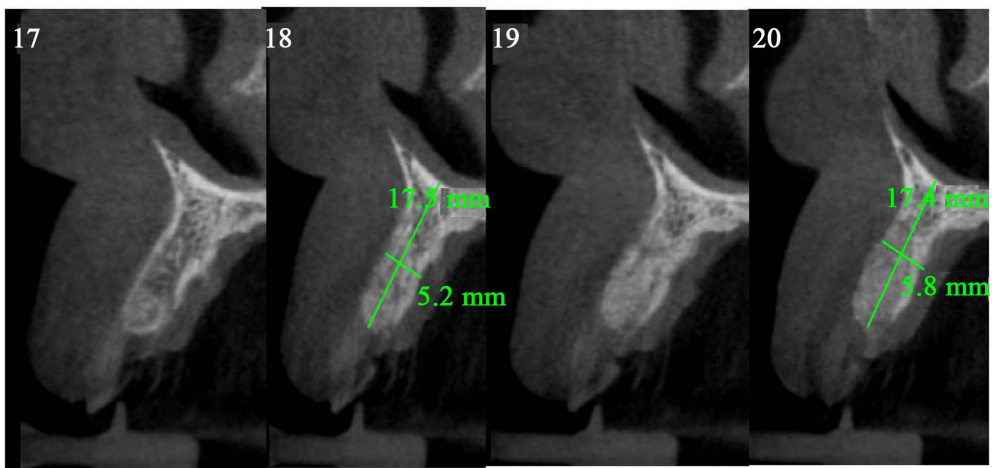

Figure 5. A CB-CT of the grafted area.

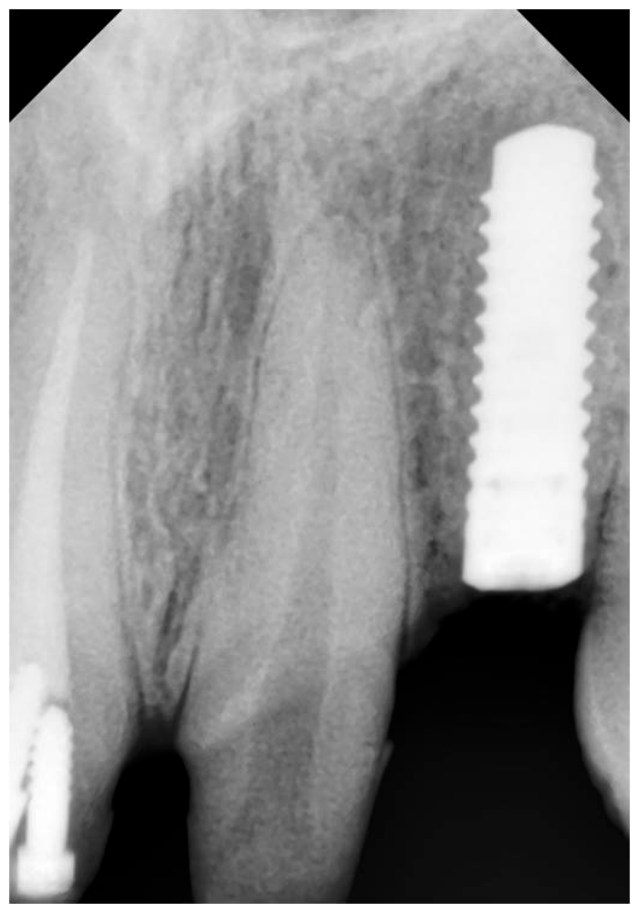

Figure 6. A periapical radiograph of dental implant. 


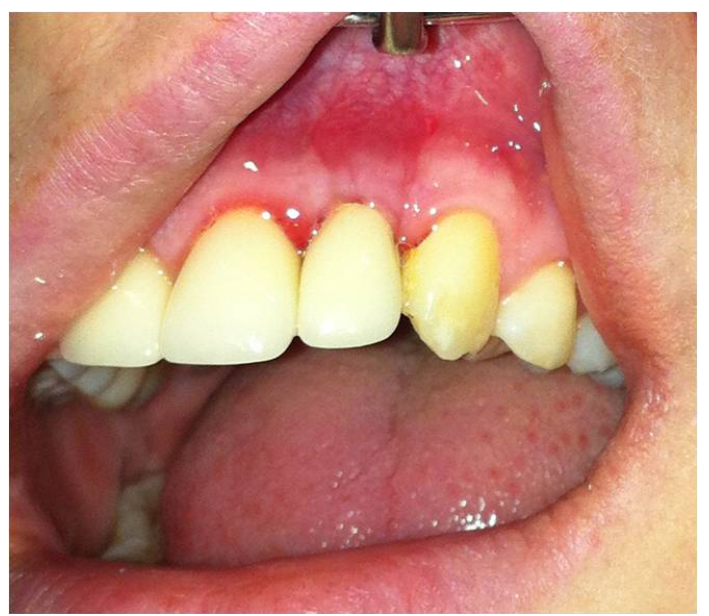

Figure 7. View of definitive prosthesis single-tooth porcelain-fused-to-zirconia restorations.

Kim et al. [15] reported that autogenous tooth bone graft material can be a preferable bone substitute for extraction socket graft because of its good bone remodeling and osteoconductivity in the series of their cases. We have reached reasonable aesthetic and functional results by using allograft.

Cheah et al. [9] demonstrated that both calcium sulfate-platelet rich plasma and calcium sulfate were effective in socket preservation application and the amount of the mineralized bone component was significantly higher in the calcium sulfate-platelet rich plasma group in comparison to the calcium sulfate group.

According to the aforementioned literature, if the volume of the alveolar ridge can be maintained after extraction of tooth, dental implant insertion would be simplified. Although insertion of dental implants right after tooth extraction is a valid treatment method, extraction and grafting socket procedure is more pertinent for treatment of fractured teeth with granulation tissue.

\section{Conclusion}

Although dental implants insertion right after tooth extraction are a valid treatment application, extraction and grafting socket procedure is more suitable for treatment by implant of fractured teeth with granulation tissue.

\section{References}

[1] Araujo, M.G. and Lindhe, J. (2005) Dimensional Ridge Alterations Following Tooth Extraction. An Experimental Study in the dog. Journal of Clinical Periodontology, 32, 212-218.

http://dx.doi.org/10.1111/j.1600-051X.2005.00642.x

[2] Bartee, B.K. (2001) Extraction Site Reconstruction for Alveolar Ridge Preservation. Part 1: Rationale and Materials Selection. Journal of Oral Implantology, 27, 187-193. http://dx.doi.org/10.1563/1548-1336(2001)027<0187:ESRFAR>2.3.CO;2

[3] Barone, A., Ricci, M., Tonelli, P., Santini, S. and Covani, U. (2013) Tissue Changes of Extraction Sockets in Humans: A Comparison of Spontaneous Healing vs. Ridge Preservation with Secondary Soft Tissue Healing. Clinical Oral Implants Research, 24, 1231-1237.

[4] Andreasen, F.M., Andreasen, J.O. and Andersson, M.C. (2007) Textbook and Color Atlas of Traumatic Injuries to the Teeth. 4th Edition, Blackwell, Oxford.

[5] Pietrokovski, J. and Massler, M. (1967) Alveolar Ridge Resorption Following Tooth Extraction. Journal of Prosthetic Dentistry, 17, 21-27. http://dx.doi.org/10.1016/0022-3913(67)90046-7

[6] Lekovic, V., Camargo, P.M., Klokkevold, P.R., Weinlaender, M., Kenney, E.B., Dimitrijevic, B., et al. (1998) Preservation of Alveolar Bone in Extraction Sockets Using Bioabsorbable Membranes. Journal of Periodontology, 69, 10441049. http://dx.doi.org/10.1902/jop.1998.69.9.1044

[7] Milani, S., Dal Pozzo, L., Rasperini, G., Sforza, C. and Dellavia, C. (2014) Deproteinized Bovine Bone Remodeling Pattern in Alveolar Socket: A Clinical Immunohistological Evaluation. Clinical Oral Implants Research. http://dx.doi.org/10.1111/clr.12535 
[8] Kotsakis, G., Chrepa, V., Marcou, N., Prasad, H. and Hinrichs, J. (2014) Flapless Alveolar Ridge Preservation Utilizing the "Socket-Plug" Technique: Clinical Technique and Review of the Literature. Journal of Oral Implantology, 40, 690-698. http://dx.doi.org/10.1563/AAID-JOI-D-12-00028

[9] Cheah, C.W., Vaithilingam, R.D., Siar, C.H., Swaminathan, D. and Hornbuckle, G.C. (2014) Histologic, Histomorphometric, and Cone-Beam Computerized Tomography Analyses of Calcium Sulfate and Platelet-Rich Plasma in Socket Preservation: A Pilot Study. Implant Dentistry, 593-601. http://dx.doi.org/10.1097/ID.0000000000000148

[10] Gurbuzer, B., Pikdoken, L., Tunali, M., Urhan, M., Kucukodaci, Z. and Ercan, F. (2010) Scintigraphic Evaluation of Osteoblastic Activity in Extraction Sockets Treated with Platelet-Rich Fibrin. Journal of Oral and Maxillofacial Surgery, 68, 980-989. http://dx.doi.org/10.1016/j.joms.2009.09.092

[11] Karaca, Ç., Er, N., Gülşahı, A. and Köseoğlu, O.T. (2015) Alveolar Ridge Preservation with a Free Gingival Graft in the Anterior Maxilla: Volumetric Evaluation in A Randomized Clinical Trial. The International Journal of Oral \& Maxillofacial Surgery, 44, 774-780. http://dx.doi.org/10.1016/j.ijom.2015.01.015

[12] Seibert, J.S. (1993) Treatment of Moderate Localized Alveolar Ridge Defects. Prevention and Reconstructive Concepts in Therapy. Dental Clinics of North America, 37, 265-280.

[13] Misch, C.E., Dietsh-Misch, F. and Misch, C.M. (1999) A Modified Socket Seal Surgery with Composite Graft Approach. Journal of Oral Implantology, 25, 244-250. http://dx.doi.org/10.1563/1548-1336(1999)025<0244:AMSSSW>2.3.CO;2

[14] Altuğ, H.A., Sahin, S., Sencimen, M. and Dogan, N.( 2009) Extraction of Upper First Molar Resulting in Fracture of Maxillary Tuberosity. Dental Traumatology, 25, e1-e2. http://dx.doi.org/10.1111/j.1600-9657.2008.00712.X

[15] Kim, Y.K., Yun, P.Y., Um, I.W., Lee, H.J., Yi, Y.J., Bae, J.H. and Lee, J. (2014) Alveolar Ridge Preservation of an Extraction Socket Using Autogenous Tooth Bone Graft Material for Implant Site Development: Prospective Case Series. Journal of Advanced Prosthodontics, 6, 521-527. http://dx.doi.org/10.4047/jap.2014.6.6.521

[16] Nair, K.R., Das, A.N., Kuriakose, M.C. and Krishnankutty, N. (2013) Management of Crown Root Fracture by Interdisciplinary Approach. Case Report in Dentistry, 2013, Article ID: 138659.

[17] Gu, Y.X., Shi, J.Y., Zhuang, L.F., Qiao, S.C., Xu, Y.Y. and Lai, H.C. (2014) Esthetic Outcome and Alterations of Soft Tissue around Single Implant Crowns: A 2-Year Prospective Study. Clinical Oral Implants Research, 26, 909-914. http://dx.doi.org/10.1111/clr.12408

[18] Buser, D., Wittneben, J., Bornstein, M.M., Grutter, L., Chappuis, V. and Belser, U.C. (2011) Stability of Contour Augmentation and Esthetic Outcomes of Implant-Supported Single Crowns in the Esthetic Zone: 3-Year Results of a Prospective Study with Early Implant Placement Postextraction. Journal of Periodontology, 82, 362-364.

[19] Al-Nsour, M.M., Chan, H.L. and Wang, H.L. (2013) Effect of the Platform-Switching Technique on Preservation of Peri-Implant Marginal Bone: A Systematic Review. International Journal of Oral \& Maxillofacial Implants, 27, 138145.

[20] Covani, U., Marconcini, S., Ferrini, F., Gelpi, F., Finotti, M., Barone, A. and de Santis, D. (2014) Posttraumatic Use of Dental Implants Immediately after Tooth Extraction: Clinical Study. Journal of Craniofacial Surgery, 25, 796-798. http://dx.doi.org/10.1097/SCS.0000000000000522 